\title{
Ecosystem Principles as Tools in Sustainable Economic Developments
}

\author{
Farounbi Adebayo Ibikunle \\ School of Science, Osun State College of Education, Ila Orangun
}

\begin{abstract}
With the economic development and population growth, humans have changed ecosystems more rapidly and extensively to meet the rapidly growing demand for food, fresh water, shelter, fibres and fuel. This has led to a substantial and largely irreversible loss of the biodiversity on earth. The ecosystem approach is created as a new concept to understand the environmental problems in economic development. Therefore, it is important to develop an ecological sustainable approach to economic development especially in the areas of urbanization, industrialization, agricultural, tourism and river basin development. Despite social, economic and political barriers to proper ecological consideration, it is urgent and imperative for human society to read between the lines of the environment and act fast so as not to destroy the environment upon which his existence depends.

Key Words: Conservation, Ecosystem, Economic, Development, Resources, Projects.
\end{abstract}

\section{Introduction}

In modern economies, various types of human activities, including agriculture, industry and transportation produce a large amount of wastes. Soil, air and water have traditionally been used as sites for the disposal of these wastes. With the development of industry, the human activities have led to a series of ecological and environmental problems such as species extinction, land degradation and global warming, which lead to the degradation of environmental quality, impact the quality of human life seriously and constrain the sustainable development of society and economy (McDonald et al., 1997; Cook et al., 1999). There have been frequent ecological problems which directly threat the human survival in recent years, for example, Chernobyl nuclear accident, water pollution in Songhua River, pollution of oil exploitation in Arctic and Niger delta, and arsenic pollution in Yangzonghai Lake in China, all of which raise more and more concern for how to avoid and alleviate the loss from ecological disasters (Qin and Zhu, 2000; IAEA, 2006; World Wildlife Fund, 2007). There have been a lot of researches on the ecological environment in many countries all over the world in order to control the regional environmental degradation and improve the living environment of human beings; researches on environmental assessment have also continually deepened (Wallack and Hope, 2002; Moraes and Molander, 2004; Wang and Zhang, 2007).

The environment by virtue of man's entire dependence on natural resources and land remains the only means of sustaining life on earth. The genesis of the environmental problem can be traced to the developed world where the beliefs in the infinite nature of the environment and the ability of technology to overcome environmental limitations led to a carefree attitude to environmental issues and practices. But the emerging reality shows that far from being infinite, the environment is basically finite. In other words, we can hardly increase the environment. Definitely, one can reclaim land from the sea or engage in some other form of changing the basic use pattern of part of the physical environment. But, the reclamation of land from the sea does not in any sense add to the total environment but increases available land space while narrowing the expanse of the sea (Adejoh, 2011).

The objective of this paper is to highlight some ecological principles that need to be observed in economic development so that natural ecosystem might not be seriously infringed. It also aims to provide some scientific reference for formulating ecological protection measures and promoting the sustainable economic development.

\section{Ecology and Ecological Principles}

Ecology is the study of the interrelationship between organisms and their environment. It involves the study of the structures and functioning of the ecosystems as the largest functional unit of the environment. It is an integrating science which brings specialized knowledge acquired in different study areas such as Agricultural Science, Chemistry, Geography, Physics, and so on; to bear in understanding the interrelationship between the environment and organisms. The aim is to enhance the goal of economic development on natural resources and the processes of the larger environment. Ecosystem in this context is a group of organisms and their environment interacting as a connected whole, characterized by energy flow, nutrient cycling, succession stages and productivity. The environment is the totality of the external surrounding of an organism. 
The plants, animals and microorganisms that live in an area and make up a biological community are interconnected by an intricate web of relationships, which includes the physical environment in which these organisms exist. These interdependent biological and physical components make up what biologists call an ecosystem. The ecosystem concept emphasizes the functional relationship among organisms and between organisms and their environments. These functional relationships are exemplified by the food chains through which energy flows, as well as by the pathways along which the chemical elements essential to life move through the ecosystem. If not intercepted, these pathways are generally circular. The elements pass through the system in cycles. An understanding of the flow of energy and the cycling of materials in ecosystem is essential to our perception of what is perhaps the most subtle and dangerous threat to man's existence. This threat is the potential destruction, by human activities, of those ecological systems upon which the very existence of the humans depends.

Principles of ecology are concepts that are observed to maintain the ecological stability of a community. Such principles should guide the nature and rate of resource exploitation, waste generation and population growth. Some of the principles are highlighted below:

a) The first principle of ecology according to Dasman et al (1973) is to keep a range of resource use options available to present and future generations. This is very important since we cannot conveniently assess the direction of technological advancement, population, needs and adaptive potential of future generations.

b) The next principle also applies to exploitation of wildlife for agricultural and pastoral development. It has been observed, with few exception that greater returns exist for such development through enhancing or improving yield from already developed areas of known and proven productivity than from converting wild and probably marginal lands to some highly productive form of commodity use (Dasman et al, 1973). This is because the present settlements resulted from experiment by several generations of agriculturebased societies and we would do well to learn from their experience.

c) The concept of carrying capacity is a very important ecological principle and the fulcrum upon which every other principle rotates. It is defined as the maximum population of a species which a particular environment can sustain indefinitely without damaging the ecosystem upon which it depends. Sustain here means the supply of natural resources and assimilation of wastes. Carrying capacity has several levels which include: subsistence, security and optimum population densities; with increasing comfort and health in the reverse order. Carrying capacity is not fixed and fluctuates naturally with the factors of climate and atmosphere; fires and floods; and earthquakes and volcanoes (Dasman et al, 1973). Human population growth has not taken into account the concept of carrying capacity. The growth of human population with the attendant developmental projects has led to urbanization and concentration of humans into urban centres. As population grows so does industries, which pours into our water supplies a vast array of contaminants. As population and industries grow, there will be need for increased agricultural production, which results in heavier pollution of soil and water. With the spread of pollution goes the threat of epidemics and chemical poisoning.

d) The next ecological principle applies to harvest of natural resources. The harvest rate of renewable resources should not be in excess of their capacity for regeneration. Harvest should also not break the energy flow in the ecosystem. In other word, it should not be concentrated on a particular type of organism or similar organisms so that the state of equilibrium of that ecosystem will not be disturbed. Harvest of non-renewable resources should be arranged so that upon their depletion, alternatives are in place which preferably should be renewable resources. This will necessarily involve optimization of the efficiency with which they are used.

e) The next principle is that the stability of an ecosystem should not be interfered with through the dumping of wastes that the system will not be able to break down immediately. Waste flow to the environment should be kept at or below the assimilative capacity of the environment.

\section{Conservation Consciousness}

The realization, in recent times that the very existence of man is threatened by his own activities has led to a new concern for the environment. This new thinking has found expressions in the following development. The United Nation's 1972 Stockholm declaration states in part that:"man has the fundamental rights to freedom, equality and adequate conditions of life in an environment of a quality that permit a life of dignity and well-being and that he has a solemn responsibility to protect and improve the environment for the present and future generation" (principle 1); that "man has a special responsibility to wisely manage the heritage of wild life and its habitat" (principle 4); that "economics and development are essential for ensuring a favourable working and living environment for him" (principle 8); that "rational planning constitute an essential tool for reconciling the conflict and preserve the environment" (UNO, 1972). Arising from the Stockholm declaration, the general assembly of the United Nations Organization in 1972 established the United Nations Environmental Programme (UNEP) by resolution 2997. The major aim of setting up UNEP was to encourage 
and support an integrated approach to planning and management of developments including natural resources, so as to take care of environmental consequences to maximize social, economic and environmental benefits.

According to Westing (1996), the World Charter for Nature announced principles of conservation in 1982 by which all human conduct affecting nature is to be guided and judged. Among them are: "Nature is to be respected and its essential processes shall not be impaired" (Principle 1); that "man's need can be met through proper functioning of natural system" (principle 8); that "living resources shall not be used in excess of their capacity for regeneration" (principle 10).

The above resolutions are aimed at securing an improved quality of life for man through wise management of the environment. This goal will be very difficult, if not impossible to attain without incorporating ecology principles into development planning.

\section{Economics of Natural Resources}

Natural resources, referred to in economics, as natural capital stock is broadly classified into renewable and non-renewable. Renewable resources are based on current influx of solar energy and hence can be regenerated. They include such resource base as forest, fisheries wild life and so on. Non-renewable resources cannot be regenerated and their usefulness can only be extended by recycling which is never $100 \%$ efficient (Christian et al 1986). They will eventually be exhausted so long as the harvest rate is positive.

There are many economic theories and environmental ideologies. The interaction between economic development and environmental integrity as seen by a classical economist is the one in which environmental degradation is allowed so long as the gains from the action causing the degradation are greater than the benefits of preserving the area in their original form (Pearce and Turner, 1990). The ecocentrists believe that the environment should not be exploited. The compromise lies in the scientific approach; exploit judiciously to minimize wastes generation. This approach seems wiser since development is a necessary component of the human societies.

The true cost of our environmental destruction has never been subjected to proper accounting. The credits are localized and easily demonstrated by the beneficiaries, but the debts are widely dispersed and borne by the entire population through the disintegration of physical and mental health; and even more importantly, by the potentially lethal destruction of ecological systems. The point is that the magnitude of environmental problems has become so great that the eventual survival of the human race on earth is quite uncertain. In developing nations like Nigeria where concern with the environment is at best at the back-burner of public discourse, the challenges of daily living made safe environmental practices largely out of the realm of the worries of the ordinary man. In spite of the existence of environmental protection agencies at both federal and state levels, a meaningful monitoring of environmental practices both at household and industrial levels is almost non-existent (Iyaji, 2011). Rather than calling for economic growth to be reined in, more recent developments turn on the notion of environmental and sustainable development. The concept of sustainable development is of recent origin. It was first used by World Conservation Strategy presented by the International Union for the Conservation of Nature and Natural Resources in 1980. It was commonly used and defined for the first time by the Brundtland report, entitled "our common future" of The World Commission on Environment and Development in 1987 (Pearce et al, 1990).

Sustainable development is therefore defined as meeting the needs of the present generation without compromising the needs of the future generations. It is one of the Millennium Development Goals (MDGs) which have been adopted by many nations of the world as they aim to reduce many forms of poverty in the coming decades (Giddens, 2006).

\section{Economic Development}

Development involves the use of materials generally in a positive way. This has made development desirable or necessary in human societies. In this vein, some questions are raised as to what is, and how is it to be developed? This is where ecology comes in. The world Conservation Strategy (1908), defines development as the use of financial and material resources to satisfy human needs and improve the quality of human life. According to Hoeberry (1983), environmentally sound and sustainably development is the one that avoids causing environmental degradation and consequent loss of social, economic welfare and avoids loss overtime of natural systems productivity through reduction in the stock of renewable resources or disturbance of the balance of natural ecosystems.

What is apparent from the above definitions is that development is a means of meeting the needs and aspiration of people through capital creation and or use of existing capital more efficiently. According to Pearce et al (1990), economic development involves the following:

a) Increase in real income per capita; b) improvement in health and nutritional status; c) access to resources; d) access to education; e) fair distribution of income. 
That development is desirable is expressed in the upsurge of interest in various nations in the planning financing and implementation of various development schemes. Economic development is an integrated process which may lead to the modification of the environment. However this is not applicable to all development processes. When economic development results in environmental stress and strain, the ecological stability of the region become disrupted and threatened.

\section{Economic Development and Environmental Degradation}

Economic development is almost always associated with reduction in the quality of the environment. This is as result of exploitation of natural resources at rates excess of their capacity for regeneration and the disposal of the resultant wastes in the environment at rates higher than its assimilation capacity. All forms of degradation result indirectly or directly from the above.

The development of industries started in Western Europe during the nineteenth century (Brggs and Smithson, 1995). As the industrial civilization is spreading, a country's development status is measured by the number of smoking stacks dotting her skyline. Between 1950 and 1970, the rate of world industrial growth exceeded that of any comparable period in the last century (Briggs and Smithson, 1995). The industrial development has added a new dimension to the environment namely: the introduction of new substances into the air, water and soil. These materials were otherwise present in harmless states or quantities before. The new approach in managing industrial development to take care of the problems of industrialization is known as "industrial ecology". Industrial ecology is concerned with the shifting of industrial process from linear systems, in whch resources and capital investments move through the system to become waste, to a closed loop system where wastes can become inputs for new processes.

Population growth and affluence combine to escalate the problems of degradation. According to Westing (1996), humans have taken over $17 \%$ of the forests and grassland of the world for their crop plants. Humans and their associated livestock have displaced $25 \%$ of the world's terrestrial animal biomass. Most are extensively exploited except only $5 \%$ of land and $0.2 \%$ of ocean which have been formally set aside as reserve. Urbanization is the dominant demographic trend of the late twentieth century. The number of people living in cities increased from six hundred million in 1950 to over two billion in 1986. If this growth continues unabated, more than half of humanity will reside in urban areas shortly after the turn of the century (Brown and Jacobson, 1987). Resultant signs of urban stress now apparent around the world call into question the continuing expansion of cities. Land and water scarcity, inefficient energy use and waste disposal, and the resultant problems of pollution all contribute to the escalating ecological and economic costs of supporting modern cities. Accelerated urbanization in the Third World has spurred the concentration of political power within cities, leading to policies that favour urban over rural areas. Now, mounting external debts are forcing Third World governments to scale back urban subsidies just as the demand for services multiplies (Brown and Jacobson, 1987). Today's urban areas are larger and more numerous than ever; have outgrown the capacity of natural and social systems to support them. One way of reaching a nation's optimum rural-urban balance would be for a market economy to play a more prominent role in economic development.

Various forms of environmental degradation associated with economic development include: depletion of natural resources, loss of species diversity, pollution, desertification, deforestation, erosion, climate change and induced natural hazard.

\section{Ecological Principles and Economic Development}

Conservation and development are not necessarily conflicting but are mutually working towards the same goals, improving man's quality of life. Ecology in the context of economic development implies; defining the ecological framework, assessing the needs for intervention and evaluating the side effects. Development can only lead to sustainable resource exploitation, if through the use of inputs and technology a level of production can be reached in which; inputs can be sustained both economically and ecologically. Natural regulatory mechanisms which are disturbed by the changes so induced can be replaced by artificial ones. In other words, development should be characterized by maintaining the system's basic ecological cycles and flows, either artificially or naturally (Christian et al, 1986)

Sustainable economic development which according to WCED (1987) is the one which has the ability to meet the needs of the needs of the present without compromising the ability of the future generations to meet their own needs, can only be attained with the understanding and application of ecological principles. A starting point is to find ways of development which uses less energy and materials as well as reducing wastes generation.

Man is part of, and depends on the continued functioning of several ecosystems in the biosphere for his own existence. The concept of carrying capacity is as applicable to population growth as it is to resource exploitation. One way of pursuing sustainable development is through optimal resource utilization. This may involve modernizing some exploitation and systems. Efficient resource exploitation system without additional 
input of nutrient will usually result in higher yield in the short term at the expense of high depletion rates. This is a major factor in environmental degradation. The system will remain stable only when the rate of exploitation is below the carrying capacity of the system (Christian et al, 1996). The same principle is applicable in growth of urban centres to ensure that cities have appropriate "ecological foot-print".

For development of natural resources to be sustainable, the ecology of the resource and the region being developed should be understood and taken into consideration. Such resources to be developed include:

(a) Development in Humid Tropical Lands: The forested tropics give an impression of highly fertile soil because of the luxuriant vegetation cover. The fertility results from nutrient cycling between plants, animals and the soil. Once the forest is cleared for agricultural purposes, improved yield may exist only for the first two seasons, nutrient depletion and degradation soon follow and savannization may follow over-exploitation.

Of all the various soil classification in the tropics only the andosol and fluvisol have the fertility and stability suitable for sustained agriculture. In accordance with ecological principles, two major sustainable pastoral developments have evolved, the one based on restricted areas of fertile soil and shifting cultivation of long duration of fallow to ensure forests colonization (biotic succession) of abandoned area (Dasman et al, 1973).

Forestry involves all commercial goods biodiversity and genetic resources and environmental services which can be derived from the forest. Commercial goods, e.g. timber, fuel-wood and non-wood products, scientific and aesthetic values can be derived from the forests. While the environmental services of forest include soil protection, moisture retention, erosion prevention climate regulation, reduction of global warming. When ecological principles are applied to forestry, the rate of harvest would not exceed capacity for regeneration and degradation would be avoided.

Road building is often seen as a means of getting from one location to another in the tropics. Construction of road through previously wild or unsettled areas will obviously open such areas to exploitation. It is important that in such cases the construction be preceded with land capability surveys, land use planning and effective land use control (Dasman et al, 1973)

(b) Development of Pastoral Land in Semi-and Sub-arid Regions: These climatic regions offer great development opportunity for enhancing the well-being of the people. Such lands are used as grazing areas for livestock, because of the delicate ecological characteristics of these areas special attentions should be paid to land management, in particular to control the number and distribution of grazing animal. The most important ecological principle in this respect is the carrying capacity of the land in other to maintain productivity and avoid over-grazing and desertification.

(c) Development of Tourism: Visitors are attracted to certain environmental resources that have outstanding beauty, recreational and educational values and sometimes exotic quality. Development of tourism differs from other forms of development where environmental degradation is traded off for some economic benefits. Here, the quality of the environment is the basis for the existence of the industry. Ecological problems encountered in the development of tourism are associated with the delicate nature of such resources; as such they can easily be destroyed, degraded by disturbances (Budowski, 1976).

In the development of tourism, the most important concern is the preservation of the natural resources in question. This would necessarily involve assessing and estimating the carrying capacity of the environment to be able to quantify the extent of appropriate development. Leisure centres, road, and so on, should not be allowed to interfere too much with the environment.

(d) Agricultural and River Basin Development Projects: The aim of agriculture is the provision of food and fibre. This would obviously modify the environment to some degrees depending on the practices and technique applied. Farming in forested areas would involve tree felling, clearing of forest, pest and weed control. Some of the changes brought about by this might lead to serious degradation of the environment without appropriate mitigation measures. Such mitigation measures include restricted cultivation, shifting cultivation and bush fallow, integrated pest control, and so on.

The need to control water supply gave rise to river basin project. Ten per cent of the world's total stream flow is now controlled particularly in the form of reservoir and irrigation projects (Dasman et al 1973). Notwithstanding the benefits of river basin projects, attention should be paid to their possible environmental impacts which range from public health concern to general ecosystem modification. It is advisable to apply ecological principles based on proper environmental and health impact assessment studies and the modification of designs to meet ecological needs. 


\section{Conclusion}

Application of ecological principles to economic development appears to be the only viable option to achieve or work toward achieving sustainable economic development. In this context it is important to assess the structure and functioning of ecosystem to ensure that development does not interfere seriously with their integrity of the ecosystem. Certain environments exist, which due to their ecological values, should be reserved from development. These include such environments that harbour the last vestige of a vanishing species and the breeding grounds of rare migratory species. This is a wise way to ensure that options for future development remain open. Above all the carrying capacity of any environment should always be considered during development to guide against degradation because, man cannot risk major modification of the biosphere except at his own risk. It should be recognized that conservation should mutually be in harmony with economic development and not necessarily in conflict.

\section{References}

[1]. Akinbami, J.F.K., Akinwumi, I.O. and Salami, A.T. (1996). Implications of Environmental Degradation in Nigeria. Natural Resource Forum, 20(4): 319 - 331

[2]. Briggs, D. and Smithson, P. (1995).Fundamentals of Physical Geography. London,Routledge.

[3]. Christian, G., Henk, B. and Eva,T.B., (1986). Ecology and Development: An attempt to synthesizeenvironmental conservation, 13(3): $211-214$.

[4]. Brown, L. R. and Jacobson, J. L. (1987).The Future of Urbanization: Facing the Ecological and Economic Constraints. WorldwatchPaper 77.

[5]. Budowaki, G. (1976). Tourism and Environmental Conservation.Environmental conservation, 3(1): 27 -33.

[6]. Dasman, R.F., Milton, J.P., and Freeman, P.H., (1973). Ecological Principle for Economic Development.London,John Wilery and Son.

[7]. Frazier, J.G., (1997). Sustainable Development: Modern elixir in sack dress. Environmental Conservation, $24(2)$ : 182 - 194.

[8]. Giddens, A. (2006).Sociology, 5th Edition. Cambridge: Policy Press

[9]. Hoeberry, J. (1983).Environmental Guidelines Survey: An analyses of Environment Procedure and Guidelines Governing Development Aids. IUCN-IIED Washington D.C. pp 81

[10]. International Atomic Energy Agency (IAEA).(2006). Environmental Consequences of the Chernobyl Accident and Their Remediation: Twenty Years of Experience. Report of the Chernobyl Forum Expert Group 'Environment'.Radiological Assessment Reports Series, Vienna.

[11]. Iyaji, A .(2011). Environmental Problems of Industrialization and Sustainable Development in Nigeria - A Review. Confluence Journal of Environmental Studies, 6:25-29.

[12]. Moraes, R, andMolander, S. (2004). A procedure for ecological tiered assessment of risks (PETAR).Human and Ecological Risk Assessment, 10: 349 .

[13]. Non-Governmental Liaison Services(1994).NGLS Handbook.. Geneva, United Nations.

[14]. Pearce, D.W., and Turner, R.K., (1990). Economics of Natural Resources and the Environment. London,Harvester Wehatsheaf.

[15]. Pearce, D.W. Barbier, E. \&Markandaya A. (1990).Sustainable Development. London, Oxford University Press.

[16]. Qin, Z. and Zhu, W. (2000).Sustainable development and pollution control in Lake Taihu. Journal of Chinese Water Resources,5: 44.

[17]. Qun'ou, J.Xiangzheng, D., Jinyan, Z. andHaiming Y. (2011). Impacts of economic development on ecosystem risk in the Yellow River Delta.Procedia Environmental Sciences 5: 208-218.

[18]. United Nations Conference on the Human Environment (1972). Stockholm, Sweden.

[19]. Wallack, R. N. and Hope, B. K. (2002).Quantitative consideration of ecosystem characteristics in an ecological risk assessment: A case study. Human and Ecological Risk Assessment, 8: 1805-1814.

[20]. Wang, and Zhang,J. A.(2007). Nonlinear model for assessing multiple probabilistic risks: a case study in South five-island of Changdao National Nature Reserve in China. Journal of Environmental Management, 85(4): 1101-1108.

[21]. Westing, A.H., (1996).Core Values of Sustainable Development of Environmental Conservation, $23(3): 218$ - 226.

[22]. World Conference on Environment and Development WCED (1987).Our Common Future.England,Oxford University Press.

[23]. World Wildlife Fund (2007).Oil spill response challenges in arctic waters.Oslo, Panda Organization.

[24]. Cook, R. B., Suter, G. W. C. andSain, E. R. (1999).Ecological risk assessment in a large river-reservoir: Introduction and background. Environmental Toxicology and Chemistry, 18(4): 581- 588. 